\title{
Analysis of Dabie Mountain tourism industry internationalization - A case study of Huanggang in Hubei
}

\author{
Xingrui Yang \\ School of Business, Huanggang Normal University, Huanggang, Hubei, China \\ Hubei Collaborative Innovation Center for the Characteristic Resources Exploitation of Dabie Mountains, \\ Huanggang, Hubei, China
}

\begin{abstract}
This paper points out the problems based on relatively backward status of Huanggang Dabie Mountain tourism internationalization: low popularity of the tourism products, insufficient international infrastructure, lack of powerful international guidance, ineffective foreign cooperation, lack of international talents and incomplete tourism product systems; according to the existing problems of Huanggang Dabie Mountain tourism internationalization, this paper puts forward the following recommendations. Huanggang Dabie Mountain tourism should open markets to break regional and industrial monopolies; actively promote regional economic cooperation of the tourism; strengthen publicity effort and broaden publicity channels; excavate universal value of the resources; guide the superior tourism enterprises to list overseas; the government needs to accelerate the international management of the tourism, in order to provide reference for further development of Dabie Mountain tourism in Huanggang.
\end{abstract}

Keywords: Dabie Mountain tourism; internationalization; Huanggang

\section{INTRODUCTION}

Huanggang City in Hubei Province is located in the Dabie Mountain area, which is one of the most famous poverty-stricken mountainous areas. The subordinated nine administrative regions have five national-level poverty-stricken counties, which are typical backward areas in central region, with a relatively weak industrial base. However, Huanggang is located in the southern foot of Dabie Mountain, with a beautiful landscape, outstanding personnel, rich eco-tourism resources and profound cultural deposits, which is also the hometown of the General; tourism industry is a pillar of economy in Huanggang, which is also an important force to drive the rapid development of other industries, and even an important way to lead the Dabie Mountain areas to overcome poverty and achieve prosperity. Huanggang is located in the inland, which has a low degree of opening in the economy, as well as the tourism industry. Faced with the trend of global economic integration and the country status of promoting a new system of open economy, this paper intends to discuss and analyze the existing problems of the tourism internationalization and puts forward constructive suggestions with the research object of Huanggang Dabie Mountain tourism internationalization.

\section{STATUS OF HUANGGANG TOURISM INTERNATIONALIZATION}

Huanggang international tourism started after the reform and opening up, and the international inbound tourism revenue was $\$ 613,000$ in 1996 . With the deep development of the reform and opening up, and the improvement of the global economic integration, the pace of Huanggang tourism internationalization gradually speeds up, and the number of the inbound tourists and foreign exchange earnings from tourism also continue to increase; however, compared with the rapid development of the domestic tourism, the foreign exchange earnings from tourism (based on the conversion at the exchange rate) and the number of inbound tourists increases slowly, and the proportion of the foreign exchange earnings from inbound tourism in the total tourism revenue decreases year by year, indicating that the level of tourism international- 
ICITCE 2015

Table 1 Basic situation of Huanggang tourism and inbound tourism in 2006 - 2014

\begin{tabular}{|l|l|l|l|l|l|l|l|l|l|}
\hline Level of internationalization & 2006 & 2007 & 2008 & 2009 & 2010 & 2011 & 2012 & 2013 & 2014 \\
\hline Number of tourists (10,000) & 324 & 466 & 585 & 660 & 819 & 1017 & 1362 & 1500 & 1800 \\
\hline Tourism revenue (100,000,000) & 20 & 27.7 & 25.5 & 30 & 44 & 55.6 & 75 & 78.3 & 100.4 \\
\hline Proportion of GNP (\%) & 5.11 & 5.85 & 4.24 & 4.11 & 5.1 & 5.32 & 6.29 & 5.87 & 6.8 \\
\hline Number of inbound tourists (10,000) & 0.6 & 0.87 & 0.94 & 1.06 & 1.17 & 1.3 & 1.47 & 0.9 & 1.32 \\
\hline Foreign exchange earnings (\$10,000) & 148.41 & 224.59 & 269.74 & 285.43 & 309.59 & 334.35 & 435.75 & 285.77 & 385.69 \\
\hline Increase of inbound revenue (\%) & - & 51 & 17 & 5 & 7 & 7 & 23 & -34 & 26 \\
\hline $\begin{array}{l}\text { Proportion of inbound tourism in } \\
\text { tourism revenue (\%) }\end{array}$ & 0.6 & 0.6 & 0.7 & 0.6 & 0.5 & 0.4 & 0.4 & 0.3 & 0.2 \\
\hline
\end{tabular}

Note: The data are obtained from Hubei Statistical Yearbook; the proportion of the foreign exchange earnings from tourism in the tourism revenue is calculated according to the current exchange rate.

ization lags behind compared with the development of Huanggang tourism. Moreover, it also lags behind compared with the degree of Dabie Mountain tourism internationalization in other regions (See Table 1).

In recent years, Huanggang tourism internationalization presents two states: first, the gradual increase of the inbound tourists, tourists from 0.6 million in 2006 increase to 1,32 million in 2014 , increase of $120 \%$;two, inbound tourism revenue accounted for the proportion of total tourism revenue gradually reduced from $0.6 \%$ in 2006 to $0.2 \%$ in 2014 .

In Wuhan city circle, the number of inbound tourism of Huanggang in recent years can rank fourth, but tourism foreign exchange income is very little, at least fifth after. This phenomenon is related to inbound tourists stay with the number of days, but also with the Huanggang Dabie Mountain tourism industry chain is not complete. Moreover, compared with other regions, the internationalization of Dabie Mountain tourism is slightly backward, compared with other domestic similar tourism resources, there is a certain gap.

\section{EXISTING PROBLEMS OF HUANGGANG TOURISM INTERNATIONALIZATION}

\subsection{Low popularity of tourism products}

Due to failure to form superior tourism enterprises, Huanggang Dabie Mountain tourism fails to establish higher brand popularity, and its popularity is lower than that of the brand of tourism products owned by the domestic famous mountains. Meanwhile, the brand creation mainly excavates red resources, which is lack of depth refining of red resources. From the perspective of deep level, a low brand popularity is related to the ineffective publicity and marketing. Most tourism enterprises possess a single means of publicity, insufficient publicity funds, non-vivid publicity image, and the marketing strategy is also to be further improved.

\subsection{Insufficient international infrastructure}

Dabie Mountain is located at the north of Huanggang City, with underdeveloped traffic, which is lack of channels in the air. The overseas tourists need to first arrive in Wuhan, and then arrive at the Dabie Mountain. Dabie Mountain crosses over multiple counties in Huanggang City, with many scenic spots. Even if the international tourists come to the Dabie Mountain, the sojourn time is reduced due to the convenient traffic, thus reducing the tourism expenses.

\subsection{Lack of powerful international guidance}

Compared with the booming tourism in Huanggang, the foreign exchange earnings from tourism have a worsening proportion in the total tourism revenue, indicating that the enterprises are lack of awareness of the international marketing, and the government and related associations and so on organizations are lack of attaching importance to the international tourism and degree of promotion. The tourism industry is an industry with more infrastructure investment. Without the promotion and guidance of the industrial policy by the government and relevant organizations, it is difficult for the enterprises to form the international competitiveness.

\subsection{Ineffective foreign cooperation}

Huanggang tourism enterprises are not only lack of powerful cooperation with the Dabie Mountain tourism enterprises in Henan, Anhui and other cities, but also lack of the depth cooperation with large domestic tourism enterprises, and even the cooperation with overseas tourism and other related enterprises. Huanggang tourism enterprises are lack of funds and international management experience in the tourism industry. Therefore, to strengthen the regional cooperation and cooperation with Europe, America and 
Asia-Pacific region is an important way to promote the tourism internationalization.

\subsection{Lack of international talents}

Huanggang tourism enterprises' the human resource of international operation and international marketing are significant insufficient. A considerable part of managers are not familiar with the international operation, do not know much about the international tourists, and unable to develop effective strategies on the international marketing. The tourism employees have a low standard of the customer service, poor service awareness, and limited foreign language skills.

\subsection{Incomplete tourism product systems}

Huanggang tourism fails to make a deep integration of the tourism resources and the elements of tourism products, and has poor convergence in the links of production, supply, sales, services, etc. and the tourism product systems are to be further improved. Moreover, the industrial chain of the leading tourism industry in Huanggang City is shorter, and the development idea of the derivatives lags behind, which is lack of tourism derivatives with the regional characteristics, brand popularity and high added value.

\section{COUNTERMEASURES OF HUANGGANG TOURISM INTERNATIONALIZATION}

\subsection{Open market to break regional and industrial monopolies}

In order to achieve further development, Huanggang tourism needs to break the regional and industrial monopolies, and further open market for the domestic and foreign countries. Firstly, it needs to encourage and guide powerful combination with tourism enterprises (groups), implement reconstruction of Huanggang tourism enterprises (groups) through mutual share participation, joint venture, cooperation, entrusted operation, joint promotion and other ways, build a large-scale cross-industry, trans-regional and trans-ownership tourism group integrated with the tourist attractions, travel agencies, hotels and entertainment, enhance the overall competitiveness of Huanggang tourism enterprises, and achieve the benefits of scale economy.

Secondly, it needs to actively use the external industrial capital to break the industrial monopoly and compensate for the insufficiency of development funds within the industry. It encourages the enterprise groups with economic strength, advanced management mode and successful experience in capital operation in the domestic and foreign finance, information, culture and entertainment, news dissemination and other industries to participate in the share of tourism industry, and reorganize the enterprise into the limited liability company with diversified investors through extensive absorption of corporate legal person, social legal person, individual private owner and other investors for share participation.

Thirdly, it is allowed to appropriately separate from the ownership and development right of the tourist attractions. Except for the scenic spots with the nature of world cultural heritage, a portion of development rights and management rights of the scenic spots can be transferred through the joint venture, stock cooperation, lease contract and other ways. In the development process, there is a need to adhere to the high starting-point planning, rational development, orderly transfer, and achieve a high degree of coordination of the development and protection.

\subsection{Actively promote regional economic cooperation of the tourism}

Dabie Mountain crosses over three provinces and eighteen cities (districts or counties), with more scenic spots. If each scenic spot does things in its own way, and fights alone, it is difficult to create Dabie Mountain as an influential and appealing brand in the country and even the world. Therefore, the further development of Huanggang tourism needs to strengthen the cooperation and interactive development of Dabie Mountain areas in Henan and Anhui; meanwhile, it also needs to rely on Wuhan Economical Circle, and strengthen exchanges and cooperation and interactive development of the regions in "Yangtze River Economic Zone", and build a quality tourist route; in addition, there is also a need to grasp the new development ideas brought by "one belt and one road", actively communicate with neighboring countries and regions, and use the resource superiority to attract foreign tourists.

\subsection{Strengthen publicity effort and broaden publicity channels}

The publicity of Huanggang Dabie Mountain tourism has made a great progress, and also has achieved a good effect. However, with the advent of the era of economic integration, some traditional promotional methods fail to meet the requirements of the times. Therefore, the publicity and promotion of Huanggang Dabie Mountain tourism must be armed with the modern technology, and also strengthen cooperation with other provinces or overseas areas, and create the overall image of the Dabie Mountain tourism by virtue of external force. Huanggang Dabie Mountain tourism should take the initiative to establish and develop the marketing alliance with major cities in the domestic and overseas tourist distributing center with a good traffic condition, such as Beijing, Shanghai, Hong Kong, Bangkok and other places, and also need to strengthen cooperation with sub-regional countries 
and the neighboring provinces. In terms of the publicity route, there is a need to actively look for innovative and attractive publicity methods. For example, it can cooperate with some animation, film and television companies, and excavate something with Dabie distinctive elements to integrate into the film and television production. Secondly, it can also actively declare the world or national culture heritage, and improve the taste and value of Huanggang Dabie Mountain tourism. Thirdly, it actively carries out international cultural exchange activities and hosts international commemorative festivals to improve the brand influence and popularity of Huanggang Dabie Mountain tourism.

\subsection{Deeply excavate universal value of the resources}

Undeniably, the red tourism resources of Huanggang Dabie Mountain have their important values. Howev$\mathrm{er}$, from an international perspective, there is a need to make a reasonable position for its past, present and future, and look for a broader development space for the cultural tourism products dominated by "red" and "green". More importantly, it should highlight the modern interpretation and connection with the red tourism resources, and actively excavate the universal valuesof red resources, or look for an organic joint point between the universal values and the local values. Therefore, the development of Dabie Mountain tourism resources must be combined with the international concept, modern trend, particularly the demand of the leisure culture in China and Western countries, in order to seek for the tourism standard that is in line with the human needs and meet the international exchange in the development of red resources.

\subsection{Guide the superior tourism enterprises to list overseas}

For some enterprises with a certain competitive advantages in Huanggang City, especially the private enterprises, there is a need to promote overseas listing and financing, expand financing channels to solve the financing problems. Compared to the domestic listing, the procedures of the overseas listing are relatively simple, and completed generally after two to four months, without requirements on the enterprise profitability. Moreover, for the tourism enterprises, the overseas listing is a kind of publicity, which has a positive impact on the expansion of its brand influence and popularity. In addition, the overseas listing will promote the tourism enterprises to improve their management capacity to some extent, because the overseas security market has higher requirements on the enterprise management ability, and also prompt the modernization and scientization of enterprise management in the case of the financial institutions purchasing more stocks of the enterprises. Thus, the overseas listing has a significant importance on the development of Huanggang tourism enterprises. The relevant departments of the municipal government should develop appropriate policies and measures or build an appropriate platform to promote the overseas listing of the tourism enterprises.

\subsection{The government accelerates the international management of the tourism}

The tourism internationalization is inseparable from the government, because in addition to the international management and operation of the scenic spots, the government also plays an important promoting role in the tourism planning, infrastructure, city image, tourism policy development, personnel training and other aspects. Therefore, Huanggang municipal government should locate Dabie Mountain in the emerging international tourist destination, construct a reasonable development space layout of the tourism industry, timely organize major international festival activities, promote the transformation and upgrading of the tourism industry, and adopt the modern information technology to build a smart tourism platform with trinity of the government, enterprise and tourists, and promote the training and introduction of the management personnel of the tourism internationalization.

\section{CONCLUSION}

Huanggang is located in the inland, adjacent to Wuhan with thorough fares of nine provinces, with unique resource endowments, adequate cultural deposits, but with a relatively weak economic development, and low degree of opening to the outside world, as well as the tourism industry as the pillar of the economy in Huanggang City. Faced with the trend of economic integration and a "new normal state" of China's economy, Huanggang Dabie Mountain tourism must make full use of the opportunity brought by "one belt and one road" and "Yangtze River Economic Zone", rely on Wuhan Economical Circle to walk on the road of opening up and development, thus improving the economic income of tourism, expanding the brand influence of the tourism products, and promoting the international development of other industries. The tourism internationalization is an effective way for the poverty-stricken Dabie Mountain areas to overcome poverty.

This paper makes an investigation on the problems existing in the tourism internationalization of the Dabie Mountain in Huanggang, and compared with the Wuhan city circle and other revolutionary tourism internationalization situation, points out the problems existing in the tourism internationalization of the Dabie Mountain in Huanggang: low popularity of the tourism products, insufficient international infrastructure, lack of powerful international guidance, ineffective foreign cooperation, lack of international talents 
and incomplete tourism product systems. And on this basis, the corresponding countermeasures are put forward: Huanggang Dabie Mountain tourism should open markets to break regional and industrial monopolies; actively promote regional economic cooperation of the tourism; strengthen publicity effort and broaden publicity channels; excavate universal value of the resources; guide the superior tourism enterprises to list overseas; the government needs to accelerate the international management of the tourism. However, the research on the internationalization of the Dabie Mountain Tourism in Huanggang is mainly confined to the tourism industry which is the macro economic factors of the tourism industry itself or the development of the tourism industry. For Huanggang City, the tourism industry as a pillar of its national economy is becoming more and more obvious, and the role of tourism and other industries is also growing stronger. So the next step can discuss Huanggang tourism internationalization and local economic linkage development mechanism from the perspective of regional economic development.

\section{ACKNOWLEDGEMENT}

This paper is financially supported by Doctoral Fund
Project of Huanggang Normal University - "Research on the Mechanism of Value Creation in the Crossborder Mergers and Acquisitions of China's Enterprises" (GN: 2015002403) and Talent Pool Project of Huanggang Normal University - "Innovation-driven Development Strategy-A Study based on Enterprises in Huanggang City from the perspective of OFDI"(GN: 2015011903)

\section{REFERENCES}

[1] [Wan Xucai, Ding Min \& Xu Feifei. 2007. Nanjing tourism international level evaluation and development conception. Economic Management, 22: 84-89.

[2] Tao Wenjie \& Liang Yushe. 2007. Tianjin international tourism competitiveness situation and promotion countermeasures. Commercial Modernization, (Late): 199-200.

[3] Yang Jinsong. 2012. Historic streets tourism development in an international perspective - A case study of Chaofu Road in Beijing. Ecological Economy, 8: 39-42.

[4] Liu Qingyu. 2013. Theme of tourism festivals in a dynamic perspective - a case study of China International Confucius Cultural Festival. Tourism Tribune, 7: 9-11.

[5] Liu Hancheng \& Xia Yahua. 2013. Research of advantages, problems and countermeasures of Dabie Mountain red tourism industry development. Journal of Huanggang Normal University, pp.10-12. 